\title{
La crisis financiera internacional y sus consecuencias para América Latina*
}

La crisis que está viviendo el mundo capitalista en la actualidad no corresponde a una depresión cíclica más, dentro de los altibajos característicos del sistema, con sus periódicas fases de expansión y contracción, sino que reviste un carácter profundamente estructural. Se trạta de un proceso muy complejo, que tal vez demore bastante tiempo en manifestarse en plenitud y en suscitar las transformaciones correspondientes.

El fenómeno no resulta sorpresivo para mí, porque soy de aquellos que postulan que el capitalismo no es algo estático, sujeto a ciclos inmutables, sino que un proceso en permanente evolución, lo que torna más complejos las situaciones y los análisis. Dentro de la crisis actual, por ejemplo, hay elementos cíclicos y otros de naturaleza estructural, mezclados, influyéndose recíprocamente.

Existe, sin duda, una crisis muy seria en el sistema financiero internacional, que afecta a todo el mundo $y$, de manera particular a nosotros los latinoamericanos. Y hay una crisis directa nuestra, que es la del endeudamiento externo de los países de la región, no de algunos de ellos, sino de la mayoría, situación que compromete en forma grave el futuro inmediato y más de largo plazo de estas economías.

\section{LA GRISIS ESTRUCTURAL DEL CAPITALISMO}

Para quienes han aprendido a visualizar el sistema económico imperante en el plano internacional no como algo ya establecido, sino como resultado de un proceso histórico y, por lo tanto, conformado por estructuras que están en constante transformación, las tensiones que se observan hoy en día no constituyen una sorpresa. Sabemos que ya desde el inicio del dinámico proceso de crecimiento y expansión capitalistas, en la postguerra, se estaban engendrando con-

*Versión editada de la conferencia que pronunció en el Centro de Estudios del Desarrollo (GED), Santiago de Chile, en enero de 1983, publicada con autorización del GED. 
flictos y contradicciones estructurales que terminarian por manifestarse y que están en la base de la situación que se vive hoy en día.

A mi juicio, el rasgo más sobresaliente de la evolución que ha experimentado a partir de entonces el mundo industrializado ha consistido en la integración de las grandes economías centrales en un solo mercado. Se ha logrado la formación de un mercado más o menos unificado en el centro mismo de la economía capitalista.

A mi juicio, el rasgo más sobresaliente de la evolución que ha experimentado a partir de entonces el mundo industrializado, ha consistido en la integración de las grandes economías centrales en un solo mercado. Se ha logrado la formación de un mercado más o menos unificado en el centro mismo de la economía capitalista.

Es una observación que no tiene nada de novedosa. La formularon hace ya bastante tiempo diversos analistas. Yo mismo escribi sobre el tema hace cosa de una década.

Ahora bien, esa integración se realizó a nivel de los circuitos comerciales $y$, también, de los financieros y monetarios. De este modo, fueron creándose nuevas posibilidades para la concentración del capital, para una difusión más rápida del progreso técnico, para una mayor homogenización de los patrones de consumo, para una circulación más eficaz de la información, etc. Todo ello hizo posible la formidable expansión de la economía capitalista inclustrializada, del centro industrial del capitalismo, que ha caracterizado el período que se abre en 1948 y se prolonga hasta 1973. La rapidez con que se consigue la integración de los mercados se manifiesta en el hecho de que las transacciones comerciales han crecido durante este lapso a un ritmo que duplica el incremento experimentado por la producción de bienes y servicios. Así, gracias a la apertura suscitada por la integración, el coeficiente de comercio exterior de estas economias se multiplicó por dos en el transcurso de este cuarto de siglo.

Una evolución de este tipo debería haber conducido al establecimiento de un sistema económico global. Es lo que tenían en mente, y con toda razón, los promotores de la llamada Comisión Trilateral. Ahora bien, un sistema económico presupone la existencia de dispositivos de coordinación para asegurar una cierta unidạd de objetivos y de comando, vale decir, requiere la existencia de centros de decisión que incorporen elementos económicos, sociales $y$ políticos.

Sin embargo, la evolución del contexto institucional estuvo en la práctica muy lejos de ser satisfactoria durante el período. En efecto, se observó un debilitamiento de los centros nacionales de decisión, esto es, una merma en la capacidad de control de sus economías por parte de los países y difícultades crecientes de coordinación interna, sin que se registrara ningún avance, como contrapartida lógica, hacia la creación de un sistema de control o de coordinación supranacional. 
Muchos son los factores que han contribuido al surgimiento de estos desajustes, de este atraso institucional, de estas limitaciones en el sistema de coordinación y control a nivel internacional. $\mathrm{Me}$ limitaré aquí a señalar algunos de ellos.

En primer lugar, están las asimetrías en el proceso de integración de los mercados, fenómeno particularmente visible en el caso de Estados Unidos. La expansión de la economía norteamericana hacia el exterior se ha caracterizado por la transnacionalización de una buena parte de sus grandes empresas. Así, el sistema productivo norteamericano conoció un fuerte crecimiento orientado hacia el resto del mundo. En esas circunstancias, Ia exportación de capitales y tecnología tuvo efectos negativos sobre las cuentas corrientes y de capital de la balanza de pagos, puesto que las empresas que se establecían en el exterior creaban mayores flujos de exportaciones hacia el mercado norteamericano. Es una situación inversa a la que vivió Inglaterra en su época clásica, en la que la exportación de capitales creaba un flujo de ingresos que tenía efectos positivos sobre la balanza de pagos y en cuenta corriente. Inglaterra pagaba gran parte de sus importaciones con ingresos que recogía del exterior. En cambio, las empresas norteamericanas se instalan en el exterior y exportan hacia Estados Unidos.

Se configura de esa forma una tendencia estructural al desequiiibrio de la balanza comercial y la de cuenta corriente. Esa situación fue beneficiosa evidentemente para el consumidor norteamericano, que tenía acceso a mercaderías de precios más bajos producidas en el exterior. Pero el estímulo a la inversión dentro del país se fue debilitando, lo que tuvo negativas repercusiones sobre la competitividad internacional de la economía de los Estados Unidos. La productividad de ésta mejoraba a un ritmo inferior a la de sus grandes competidores, mientras que el desempleo aumentaba más rápidamente en Estados Unidos, como lo demuestra el hecho de que ya en la década del sesenta exhibía una tasa de desocupación que era el doble de la imperante en Europa Occidental, relación que se mantuvo en períodos posteriores.

Se trata, pues, de desajustes estructurales que encuentran su origen en la forma como se fue integrando la economía de los Estados Unidos al sistema internacional. No debe olvidarse que en términos relativos el comercio de ese país creció a un ritmo dos veces mayor que el producto durante el período: su coeficiente de importación pasa de 4 a $8 \%$, o algo así.

La segunda fuente de desajustes estructurales que explican en último término la crisis actual, consiste en la excesiva apertura en que incurrieron numerosas economías nacionales, particularmente en Europa Occidental. Allí el coeficiente de comercio exterior, vale decir el significado conjunto de importaciones y exportaciones dentro del producto interno, pasa de 20 ó 30 a 40 ó $60 \%$, lo cual 
hizo más difícil la implementación de políticas de estabilidad interna con pleno empleo, frente a las fluctuaciones del contexto internacional. La situación revistió especial gravedad en los países de la Comunidad Económica Europea, debido a la menor autonomía de sus centros nacionales de decisión. Integrarse era de alguna manera renunciar al control de la propia economía, reducir el margen de autonomía externa. A ese resultado llevaba la exagerada apertura al exterior, en circunstancias de que, como estoy tratando de. demostrar, el contexto internacional acusaba asimetrías que anticipaban el densencadenamiento, tarde o temprano, de una crisis de una naturaleza nueva, no propiamente cíclica. La expansión de las exportaciones se transformó para Europa en condición necesaria no sólo para el crecimiento económico, sino también para el logro de un satisfactorio nivel de empleo.

El tercer factor de perturbación tuvo su origen en el funcionamiento de la economía japonesa, cuya integración al mercado internacional, a diferencia de lo que sucedió con Estados Unidos, se hizo principalmente sobre la base de una mayor participación en el comercio internacional, vía una expansión espectacular de las exportaciones. De ahí que las inversiones se hayan concentrado al interior del país, lográndose avances considerables en la productividad interna y en la competitividad en los mercados mundiales. La persistencia de la posición excedentaria en la balanza de pagos es un reflejo de esa situación estructural. Además, en contraste con lo ocurrido en países de la Comunidad Económica Europea, la integración internacional no afectó en términos negativos la capacidad de coordinación interna de la economía nipona. De allí que el Japón haya logrado conciliar los objetivos de una política orientada al mejoramiento sistemático de su competitividad internacional, con la salvaguardia del pleno empleo. Todo eso, evidentemente, se fue traduciendo en una menor autonomía de decisión de las economías que competían con el Japón.

El cuadro estructural que esa evolución produjo tenía necesariamente que afectar la dinámica del sistema global. A partir de fines de los años sesenta los países de la Comunidad Económica Europea empiezan a manifestar aprensiones con respecto a esa situación y creen que podrán encararla exitosamente vía la intensificación de los vínculos comunitarios. Pero no existían condiciones políticas regionales para avanzar en tal sentido, menos aún con la entrada por aquel entonces de Gran Bretaña a la Comunidad. El proyecto formulado en 1969 por los Jefes de Gobierno de las naciones miembros, en el sentido de fortalecer la Comunidad Económica Europea como mecanismo de decisión y coordinación, introduciéndole los carabios de estructuras que fuera menester, fracasó completamente, no sólo por la presencia de Gran Bretaña, sino por las dificultades polfticas internas que surgieron en cada uno de esos países. 
Por otro lado, la precariedad de la situación de la balanza de pagos de los Estados Unidos se hizo evidente en esa época, lo que condujo en 1971 al abandono de los acuerdos de Bretton Woods, los que no fueron sustituidos por ningún mecanismo coherente. La brusca elevación de los precios del petróleo en la segunda mitad de 1973 introdujo nuevos factores de desajuste en ese cuadro ya perturbado. Por primera vez aparecía en la escena internacional un grupo de paises que presentaban un importante excedente en cuenta corriente de balanza de pagos, pero que no estaban en condiciones de utilizarlo en el incremento de sus importaciones o en inversiones directamente productivas de capital en el exterior. Sus recursos excedentarios fueron depositados a plazos relativamente cortos en ins. tituciones financieras de otros países, las que constituyen el sistema bancario internacional, a fin de ser "reciclados", como se decía en la época, o sea, re-introducidos a los circuitos productivos, a cambio, como es natural, de un interés.

Ahora bien, los países que habian sufrido el deterioro de sus términos de intercambio a causa de la drástica elevación del precio del petróleo se dividieron en dos grupos. De un lado se quedaron los industrializados, que buscaban recuperar el equilibrio de sus cuentas corrientes vía un aumento de sus exportaciones. Del otro, se situaron las naciones del Tercer Mundo y las socialistas, que imaginaron encontrar la solución de sus problemas en el endeudamiento externo. Este segundo grupo aumentó sus importaciones de productos manufacturados en un período en que tanto la productividad interna como la capacidad para importar tendían a declinar debido al deterioro de sus términos de intercambio. La verdad es que el comportamiento de estos dos grupos de países fue complementario. Los primeros no podrían haber asumido la política que siguieron si es que no hubiese existido el segundo grupo.

$\mathrm{Si}$ 'los países industrializados lograron aumentar sus exportaciones para recuperar su equilibrio de balanza de pagos, fue precisamente porque el segundo grupo de países aumentó sus importaciones. El proceso de reciclaje de petrodólares tuvo pues dos consecuencias importantes. La primera consistió en el endeudamiento de gran número de países del T'ercer Mundo y socialistas. La segunda, en la expansión enorme e incontrolada del sistema bancario internacional.

El endeudamiento de los países del Tercer Mundo y socialistas se transformó en una fórmula mágica que les permitía mantenerse e incluso expandir sus compras en el exterior. Las economías industrializadas, por su parte, lograban aumentar sus exportaciones. Todos quedaban de esta forma contentos. Se trataba en el fondo de un fenómeno estrictamente aparente, pues lo que estaban haciendo en verdad era postergar o generar un desequilibrio mucho mayor para el futuro. Los bancos imaginaban hacer grandes nego- 
cios, sin darse cuenta de que la recesión se propagaba en los países industrializados, lo que reducía el margen de utilidad de sus sistemas productivos $y$, por tanto, la posibilidad de que les reembolsaran esos préstamos. Cabe agregar que las naciones industrializadas, al aumentar sus exportaciones reales con el objeto de compensar la elevación del precio relativo del petróleo, creaban presiones inflacionarias intermas, las que eran contrarrestadas por políticas recesivas. De esta forma, los países del Tercer Mundo y los socialistas empezaron a encarar dificultades crecientes para aumentar sus exportaciones hacia el Norte, expansión que era absolutamente imprescindible para servir la deuda contraída. La presión que hicieron en tal sentido engendró la baja de los precios de los productos primarios, vale decir, un deterioro adicional de sus términos de intercambio.

En sintesis, cuando ya se había alcanzado el punto de inflexión del crecimiento impulsado por la integración de los mercados en el centro, y se hacía indispensable encontrar formas nuevas de coordinación en el plano internacional, se suscita el problema del "reciclaje". No se trataba, como se creyó en aquel entonces, de un simple problema de administración de liquidez internacional, susceptible de ser solucionado por los bancos. El desafío de fondo, en rigor, consistía en asegurar la transferencia internacional de activos reales, lo que exigía la creación de instrumentos adecuados de créditos y con garantías de parte de los patses encleudados. Además, se hacía necesario modificar progresivamente las estructuras de las economías nacionales y del intercambio internacional para que los países pudieren absorber en forma adecuada el impacto del aumento de los precios relativos de las fuentes primarias de energía. Sin embargo, la carencia de una percepción global de lo que estaba ocurriendo hizo pensar que el problema se limitaba a buscar clientes para utilizar los fondos depositados en los bancos. Instituciones sin experiencia ninguna en materia de crédito especializado pasaron de la noche a la mañana a administrar enormes e ingentes masas de recursos financieros en los mercados internacionales.

Me parece necesario insistir en que las consecuencias negativas de la pérdida de autonomía de los centros nacionales de control y coordinación ya eran evidentes antes de las bruscas elevaciones de los precios del petróleo. Esa situación se vio agudizada debido a la enorme expansión del sistema financiero internacional y a la parálisis de gran número de gobiernos a causa del excesivo endeudamiento.

La pregunta que cabe formularse es cómo evolucionará este cuadro en el futuro previsible. En el pasado, las crisis del capitalismo llevaron a un reforzamiento de los sistemas nacionales. La situación presente se caracteriza por el fenómeno inverso, por el debilitamiento de la participación de los Estados nacionales, no sólo en el 
plano económico, sino además en el ámbito social. Toda esa participación del Estado empieza a ser cuestionada. Este deterioro no ha sido compensado por una efectiva cooperación al nivel de las empresas transnacionales, con el objeto de comenzar a suplir las deficiencias de los Estados, en la línea de lo que pareció postular el proyecto de la Comisión Trilateral. Lo que sucede es que las empresas transnacionales no tienen solución que ofrecer para el problema del desempleo que aflige a los países centrales.

Las cosas van evolucionando entonces como si estuviéramos frente a una situación de impasse. Se debilitan gradualmente los centros de decisión nacionales, hasta que sobreviene la crisis, pero ésta no restaura ese poder de decisión, a diferencia de lo que sucedió siempre en el pasado con estas emergencias. El proyecto de coordinación transnacional, de una inteligencia nueva, en el que se depositaron muchas expectativas hace alrededor de una década, se encuentra estancado. Yo diría que cuando se está frente a una situación como ésta resulta evidente que no entendemos la realidad. Una crisis de naturaleza nueva exige una reflexión y una visión globales, que es exactamente lo que falta hoy en día.

Guando se mira de una perspectiva global lo que está pasando, y tengo ese privilegio, pues paso la mayor parte del año en Europa y otra parte en Brasil, se perciben algunas líneas de fuerza que se manifiestan ya en diversos foros internacionales. La reunión del GATT de 1982 fue muy aleccionadora en este sentido. Uno se da cuenta, en efecto, de que en las naciones centrales la gran crisis consiste en el desajuste. Se aprecia una progresiva toma de conciencia de que en los países se está perdiendo el control de la situación; de que los centros nacionales de decisión se han debilitado en forma excesiva. En general, se atribuye el problema a la exagerada apertura de las economías al exterior, apertura no en el sentido comercial, sino en el financiero. Se siente la incapacidad, por ejemplo, de hacer frente a la gran presión que podrían ejercer los capitales de corto plazo. Y se aprecia la necesidad de tener una política monetaria realmente autónoma, que permita reaccionar frente a modificaciones que sigue la de Estados Unidos, las cuales repercuten de inmediato en el mercado financiero internacional y, por esa vía, en los mercados financieros de casi todos los países industrializados, y especialmente en los de Europa. Japón es siempre un caso aparte, porque tiene un mayor control sobre su economfa. Es indiscutible que en Europa la gente considera que se avanzó demasiado en la apertura.

$\mathrm{Si}$ esto último es verdad, y llega a manifestarse en el terreno de las decisiones políticas, todo indica que el centro se va a dividir. No porque vaya a entrar en conflicto un país con otro, sino porque parece estar en vías de extinción la idea de un espacio de integración creciente, cuya racionalidad es definida más bien por las em- 
presas transnacionales, sobre todo en lo concerniente a la asignación de recursos. Frente a la crisis, en el pasado se buscaba reforzar el sistema nacional; con la crisis actual, aparentemente se camina hacia el fortalecimiento de los grandes bloques. Esta es una clara ruptura con el pasado. Yo no sabría decir si van a surgir tres o cuatro grupos, ni sé si Europa va a permanecer como un solo sistema. En fin, también es posible que los europeos se den cuenta, de eso se habla mucho allá, de que es necesaria una política global para la región, especialmente en el plano de la tecnología y del comercio. En tal evento, se podría concretar realmente la formación de un sistema económico europeo. Pero es sólo una hipótesis entre las varias alternativas posibles.

En todo caso, yo no veo cómo se podría volver a la ideología que predominó hace 10 años, y que postulaba la existencia de un solo espacio. Por lo menos son tres los grandes espacios que se observan ahora. Estados Unidos está evidentemente en una situación particular. Es el sistema más fuerte, y por eso comanda el sistema monetario internacional. Pero, por otro lado, el desajuste estructural más grande encuentra su origen en la forma en que ese país se integró a los mercados internacionales. Como ha sido la economía que más avanzó en la transnacionalización de su sistema productivo, es la que tropieza con mayores dificultades para solucionar pro: blemas de balanza de pagos. Por cierto, una forma de superarlos consiste en exportar su inflación, transmitiéndola al resto del mundo. O, como ahora último, vía una elevación brutal de las tasas de interés. Pero es evidente que se trata de una situación que no puede repetirse muchas veces: agudiza su problema del desempleo y, además, carece a la larga de viabilidad, porque crea graves problemas en el resto del mundo, tanto de balanza de pagos como de empleo.

En lo tocante a Europa, el problema crucial está representado por la fragilidad de sus aparatos de decisiones; y en el caso del Japón, por la asimetría de sus relaciones con los otros dos grandes centros. Japón es, sin duda, el sistema más dinámico, pero, también, el más dependiente, porque lo que importa de Europa y Estados Unidos, es mucho más importante para él, que lo que Estados Unidos y Europa le compran. Lo que Estados Unidos adquiere en. Japón es muy importante, porque ayuda a la economía norteamericana a reducir sus costos; pero lo que importa Japón de Estados Unidos es alimentos, y en gran escala. Por lo tanto, Japón, el más fuerte, es en el fondo el que está permanentemente a la defensiva: sabe que si se camina hacia una reestructuración del sistema global, es el más vulnerable.

Lo que me interesa destacar, es que la estructura económica internacional prevaleciente hoy no admite la aplicación de una politica que lleve, en circunstancias como las actuales, a generar en 
el corto plazo una mayor demanda para inducir una reactivación vigorosa. El debate internacional acerca de las posibilidades que el actual sistema ofrece para superar esta crisis resulta inútil, porque es evidente que una reactivación acentúa los desajustes y las tensiones estructurales del sistema.

Por lo tanto, la conclusión preliminar que se puede extraer de este análisis, y que nos afecta a todos, es que posiblemente vamos a enfrentar un largo período de bajas tasas de crecimiento, de recesión, de una economía mundial muy poco dinámica, hasta que de una vez por todas se comprenda la necesidad de acometer grandes transformaciones estructurales. Parece difícil, sin embargo, que lleguen a comprender esto los lideres de las grandes economías industrializadas, particularmente de Estados Unidos.

\section{LA GRISIS DEL SISTEMA BANCARIO INTERNACIONAL}

Pasando al segundo tema que me propongo examinar aquí, diría que, más que ante una crisis del sistema financiero internacional, estamos en presencia de una crisis de la banca privada internacional. Los grandes bancos se encuentran en una situación de virtual insolvencia $\mathrm{y}$ hacen todo tipo de malabarismos para mantenerse, aunque su suerte está subordinada casi por completo a lo que hagan las autoridades monetarias, sobre todo las norteamericanas.

Es interesante observar cómo está siendo objeto de tratamiento esta crisis, ya bien reconocida, configurad̦a y diagnosticada. La verdad es que se ha avanzado bastante en ese terreno. Pero es un avance condenado al fracaso, porque no se quiere reconocer el problema de fondo. Se está promoviendo la reestructuración bancaria internacional, lo que va a traducirse en la eliminación de buena parte de las instituciones carentes de experiencia y capacidad, mil y tantos bancos pequeños que a través de los sindicatos incursionaron en este campo en la época del auge del mercado de los eurodólares. La reestructuración se está haciendo a partir de los grandęs bancos, los cuales están asumiendo las carteras de los pequeños en forma indirecta, y de la creación de un prestamista de último recurso, que ya se encuentra operando actualmente, sea a través del BIS, Bank of International Settlement, o en forma directa, a través de la Reserva Federal de Estados Unidos. Los bancos, además, han empezado a reunirse bajo el liderato de los grandes. Primero en clubes y ahora en un Instituto de Estudios recién creado.

La experiencia que tuvimos con la renegociación de la deuda brasileña ha sido muy aleccionadora. El plan de rescate fue diseñado por un comité en el cual participaron personeros de los grandes bancos, los cuales, por lo demás, condujeron las negociaciones, no dando cabida a los acreedores menores. Ningún pequeño banco pudo, por ejemplo, por decirlo así, ni siquiera esgrimir como ame- 
naza ir a los tribunales para reclamar por el no pago oportuno de un compromiso brasileño. Todo fue asumido como si se tratara de un acreedor de segunda línea, por los grandes bancos, en nombre evidentemente, del Sistema de Reserva Federal de Estados Unidos.

Quedó demostrado así -en este caso, bastante más complejo que el de México, que requería básicamente ayuda de corto plazo- que los grandes bancos internacionales asumen un papel muy definido en la solución de la crisis. Se juegan por quebrar los sindicatos a través de los cuales habían invitado a participar a instituciones de menor tamaño. Dan por entendido que, en las operaciones cle salvataje, sus respectivos bancos centrales los respaldarán, creando la liquidez necesaria.

Veamos cómo está operando esto en forma más concreta. No existe nada establecido formalmente, pero ya desde 1979 se ha venido aplicando el principio de que toda renegociación de la deuda externa presupone o exige previa o anticipadamente un arreglo con el FMI. Ahora bien, qué significa realmente eso. El Fondo es una institución creada con el objeto, según lo seĩalan sus estatutos, de ayudar a los países en la solución de problemas transitorios de balanza de pago en cuenta corriente, llamados clesequilibrios de corto plazo. En rigor, el Fondo no es nada más que una segunda línea de reserva, a la que se echa mano cuando se enfrenta un déficit en la cuenta corriente de la balanza de pagos. El Estatuto del Fondo señala explícitamente que el organismo no puede operar en materia de cuenta de capital, ni absorber ningún problema de ese carácter, ya que sus recursos no están destinaclos a estos fines. La tradición que se había consolidado durante mucho tiempo estaba en consonancia con este principio: que la cuenta de capital es de responsabilidad del país $y$, más aún, que los flujos de capital deben ser controlados nacionalmente.

Pero lo que se está observando en la práctica en muestros días, es que el FMI administra terapias de corto plazo, de shock, para encarar problemas que son indiscutiblemente de mediano y largo plazo. Es decir, está incursionando en el ámbito de la cuenta de capital. La experiencia brasileña resulta otra vez muy ilustrativa. Basta detenerse a examinar la significación que el servicio de la deuda tiene dentro de la balanza de pagos del país para percatarse de que el desequilibrio en cuenta corriente fluye de un monumental problema de endeudamiento externo. Entonces el tratamiento tradicional, consistente en comprimir la demanda interna, no sirve de nada, porque por esa vía no se va a lograr la formidable expansión de exportaciones que Brasil requeriría para servir su deuda.

Los problemas graves de balanza de pagos, de abultadas deudas acumuladas con el exterior, exigen una reestructuración de la economía $y$ deben ser encarados en el marco de una estrategia que tenga como objetivo principal el crecimiento. Porque los países con 
deudas muy grandes sólo podrán pagarlas si es que sus economías se expanden a ritmo considerable. Pero estos problemas tan profundos están siendo tratados con una terapia de shock que postula la reducción de la demanda interna, la depresión deliberada de la actividad productiva, mayores tasas de desempleo, subutilización de la capacidad instalada, todo ello con el fin de lograr, supuestamente, restablecer los equilibrios macroeconómicos.

A pesar de que los problemas de este tipo no son la especialidad del Fondo, éste ha asumido el comando de todas las operaciones para encararlos. Es el FMr el que convoca a los grandes bancos acreedores cuando un deudor entra en serias dificultades, y el que los insta a proporcionar recursos crediticios adicionales como requisito para que él intervenga.

En segundo lugar, el Fondo está exigiendo a la comunidad internacional que para la concesión de nuevos préstamos se ciña a las normas y criterios que él determina. Por ejemplo, a cada país al que el FMI le presta ayuda de emergencia, se le fija un tope de endeudamiento, que queda estipulado en el respectivo acuerdo stand-by. En el mismo convenio se establece que todo otro préstamo nuevo deberá destinarse únicamente para pagar las deudas y quedará subordinado al Fondo, hasta el punto que la liberación de esos recursos sólo deberá hacerse cuando dicho organismo libere los suyos propios. En virtud de tales acuerdos, de tres años de vigencia, todo el proceso de obtención de nuevos recursos crediticios en el mercado internacional queda bajo el control del Fondo. Yo mismo he visto minutas para nuevos préstamos, en que se establece explícitamente que los recursos serán entregados por parcialidades, de acuerdo a la forma en que el FMI vaya liberando el crédito que otorgó. Por lo tanto, diría yo que la crisis monetaria está siendo encarada en función de los criterios que sustentan los personeros de la gran banca privada y del Fondo Monetario Internacional, que es una institución que evidentemente está preocupada de problemas de corto plazo y carece de competencia en el campo del crecimiento y los equilibrios de largo plazo. Es curioso que el Banco Mundial no esté desempeñando ningún papel importante en la solución de la crisis.

Pues bien, el hecho de que la crisis esté siendo administrada por el FMI, de acuerdo a los criterios que éste maneja respecto al origen de los desequilibrios externos, implica presionar a Ios países del Tercer Mundo para que privilegien el proceso de desendeudamiento. Se subordina todo al desendeudamiento. La meta para Brasil implica alcanzar a fines de 1983 el punto cero en la expansión de la deuda, y empezar luego a reducirla. El número de nuevas ocupaciones, la tasa de crecimiento, todas las demás metas pasan a ser variables residuales.

Ante un panorama económico tan poco promisorio, con una re- 
cesión que aparentemente va a ser prolongada, crecientes dificultades en el acceso a los mercados internacionales, deterioro de los términos de intercambio, etc., una adaptación como la que postula el FMr, basada en el imperativo de pagar la deuda cuanto antes, implica exigir un esfuerzo desmesurado a los países en dificultades. Implica meternos en una camisa de fuerza, obligarlos a aplicar una politica interna de una dureza increbble, de reducción de la actividad económica, para empezar a desendeudarse justo en un momento en que todo el mundo está viviendo una fase contractiva. Pues bien, es una alternativa que carece de viabilidad. Lo más probable es que estas exigencias despierten una reacción vigorosa de rechazo en muchos pafses. Rechazo a una fórmula diseñada por banqueros y burócratas carentes de toda visión y sensibilidad política y social.

\section{CRISIS ECONÓMICA Y DEMOCRAGIA}

Me parece importante que estas cosas se digan con toda claridad y que se definan las responsabilidades, para que sepamos muy bien a quién atribuir las crisis que se pueden desencadenar en el futuro próximo en nuestros países. La suerte de la democracia en ellos depende de que no permitamos que se nos impongan estas condiciones.

Los países en desarrollo están siendo sometidos no sólo al impacto brutal del deterioro de sus términos de intercambio, sino que ahora tienen que absorber las exigencias que, con el apoyo del FMr, les imponen la gran banca internacional, con el objeto de salvaguardar el prestigio de sus ejecutivos, entonar la cotización de sus acciones en las bolsas, incrementar sus indices de rentabilidad, etc. Se trata de objetivos que para ellos pueden ser muy importantes, pero que para nuestros países no tienen ningún sentido frente a las actuales dificultades'.

Esta conclusión debe exponerse sin tapujos, insisto, de modo que no haya lugar a equívocos.

Lo que quiero señalar es que resulta imperativo que recuperemos el control de nuestras economías. A causa de la internacionaIización, todos los países, inclusive Estados Unidos, han perdido algo del control que antes ejercían internamente. Pero los países de la periferia han sido los más afectados. En particular, hemos perdido por completo el control sobre los flujos financieros, con lo que en medida importante se nos ha ido de las manos la administración de las políticas monetaria y cambiaria, que fueron tradicionalmente instrumentos poderosos de la política económica en nuestros países.

Entonces los Bancos Centrales dejan de tener sentido y hay que limitarse a observar la trayectoria de las tasas de interés. No hay política de redescuento, ni de reservas, que no sea inducir la depresión de la actividad productiva interna. 
El desafío que encaramos los países de la periferia es romper esta camisa de fuerza que nos ha significado perder el control sobre las variables macros de nuestros sistemas económicos. Es sintomá. tico que incluso los países europeos se hayan demorado mucho en abrirse a los flujos de capital: la liberalización en este plano tardó bastante más que la del intercambio comercial.

La política económica se hace con instrumentos. Para aplicar una política, cualquiera que ella sea, se requiere poder usar los distintos instrumentos teóricamente disponibles, lo cual exige recuperar el control que hemos perdido.

Hace un año yo planteaba que esta estrategia alternativa significaba iniciar de inmediato la renegociación de la deuda externa, antes de que nuestros países se quedaran sin reservas $y$, por tanto, sumidos en una situación de absoluta vulnerabilidad. Renegociación que tendría que haber ido acompañada de las antiguas, criticadas, pero imprescindibles políticas de control de cambios y de importaciones. Una estrategia de este tipo exige desvincular la deuda externa de la política del tipo de cambio, asumiendo todos los costos financieros de la necesaria devaluación. Sólo así, postulaba yo, podríamos tener una política crediticia propia. Todo esto tiene costos para la sociedad, porque implica subsidios, involucra apoyar preferencialmente a un sector más que a otro, pero la sociedad tiene que pagarlos. Lo importante es que haya consenso sobre la materia, consenso político.

En el caso concreto del Brasil, se me dijo entonces que la banca privada internacional no querría renegociar. Por supuesto que eso no le gusta, pero al final tiene que hacerlo, porque no puede dejar que un país vaya a la quiebra, pues ese sería el peor negocio para ella. Es preciso entonces utilizar la capacidad de presión que nuestros países tienen, no para negarse a pagar, sino para que el cumplimiento de los compromisos no nos imponga condiciones que pueden perfectamente evitarse.

En muchos de nuestros países están en marcha procesos de democratización, después del fracaso de experiencias autoritarias. La vuelta a la democracia exige como requisito imprescindible recuperar el control sobre instrumentos y variables cruciales en la economía. De otra manera, podría suceder que los que detentaron hasta ahora el poder mantengan en sus manos el manejo de la economía, exigiendo que la democracia imponga al pueblo sacrificios insostenibles para pagar la deuda, como si éste fuera el objetivo básico en función del cual deben movilizarse nuestros países. 